\title{
Enhancement of Transient Stability in a Grid-Connected Wind Power Plant Utilizing PI-FL Controller
}

\author{
Dr. KamalaMoorthy $\mathbf{N}^{\mathrm{a}}$, Kumaraswami $\mathbf{M}^{\mathrm{b}}$, and Naresh mothkuri ${ }^{\mathrm{c}}$
}

\begin{abstract}
aAssociate professor in Department of EEE, Malla Reddy College of Engineering \& Technology, Hyderabad, India. ${ }^{b}$ Assistant Professor in Department of EEE, Malla Reddy College of Engineering \& Technology, Hyderabad, India. ${ }^{\mathrm{c}}$ Assistant Professor in Department of EEE, Malla Reddy College of Engineering \& Technology, Hyderabad, India.
\end{abstract}

Article History: Received: 11 January 2021; Accepted: 27 February 2021; Published online: 5 April 2021

\begin{abstract}
This paper proposed a blend of corresponding PIC and FLC for controlling the pitch angle of wind turbine connected to grid. Initially, conventional control methodology is employed to design the PI controller and later on, the concept of fuzzy logic methodology is adapted to analyze the gains of proportional integral controller. Due to versatility of fuzzy logic controller and rugged structure, sturdy nature of proportional integral controller are clubbed together, it provides a virtuous stagnant and dynamic outcomes. The proposed novel technique can be assessed by considering various disturbances such as short circuit network fault. The reenactment after effects of proposed controller is contrasted with proportional integral controller and FLC. From the findings it is shown that the proposed methodology could improve stability even the wind farm is subjected to different operating conditions. Moreover, a performance index in terms of absolute maximum deviations is defined in order to evaluate the adequacy of the proposed controller.
\end{abstract}

Keywords: Fluctuations, FLC, STATCOM, PI, Hybrid and Pitch angle controller, Pole-placement, Wind farm.

\section{Introduction}

Over last two decades, due to the excessive emission of greenhouse gases into the atmosphere, the climate change all over the world has become a major concern for the developed as well as developing countries. Since conventional power plants are the major contributors of greenhouse gases, the efforts are being made to meet out the electrical energy needs, as much as possible, take advantage of renewable energy sources like solar and wind energy. $\mathrm{n}$ modern scenario, wind and solar power have become very popular due to their renewable quality in nature. Furthermore, as a result of its lower costs, wind vitality continues to keep competing with conventional energy, with advances in technology and incentives to adopt renewable energy since the last decade.

These natural variations in electricity have negative effects on the electric grid to which the wind farm ties. In addition, the Wind farm's output differs in some range because of unusual wind speed characteristics. Therefore, the operating point of the power system changes regularly as the wind power network is incorporated into the power grid. Almost all of the research deals with the elimination of power variability in an optimized wind power system. According to some reports, Braking Resistors (BR) can be employed for stabilization of induction generator (A. Causebrook, 2007; R. Ghazi, 2010). It consumes active power and costlier than pitch angle control. Recently, Superconducting Magnetic Energy System (SMES) has also been employed for grid connected wind generator stabilization (M. R. I. Sheikh, 2012). Moreover, in the event of faults, the Super Conducting Fault Current Limiter (SCFCL) can suppress short-circuit current thereby, it can improve transient stability of induction generator, and it still more complex than BR (Ou, R., 2015). Many researchers have advised the hybrid controller in different areas. A hybrid speed controller is proposed in (A. S. Yilmas, 2009; Latchoumi, 2017) for interior permanent magnet synchronous motor (IPMSM) drives to enhance the state responses are dynamic and steady. Fuzzy PID type device has been proposed to monitor the excitation of a generator connected to power grid (M. N. Uddin, 2011). In (L. Reznik, 2000; Aroulanandam, 2020), Proportional Integral controller appended with FLC is utilized on the STATCOM damping controller to boost the power quality and reliability of the wind farm which is connected to power system. The active power suppression of the wind turbine generator using PI-FLC for the pitch-angle controller was addressed in (L.Wang, 2013), where the base values of PI controller gains have been considered using trial-anderror method which is not suitable. In (P. Garasi, 2014), hybrid pitch-angle controller for SCIG wind turbine system has been proposed, however the base values of PI controller gains determined using Ziegler-Nichols rules have the severe limitations. One of the limitations of these rules exhibit starting values that will work with many processes but are not generalized to work with all processes. In comparison, the PI controller operates with the above-average wind speed while the fuzzy logic controller operates when the wind speed is lower than that measured, the frequency fluctuation shall be smoothed out as well as the overall power output of the loop. So the PI Controller and the Fuzzy controller have their specified separate range for wind speeds and works independently in their respective range. Motivated by this work, this paper proposes a truly hybrid control strategy for maximum power-point tracking (MPPT) and pitch-angle control based on PI and fuzzy techniques. (i.e. for the wind speed below as well as above 
rated speed) for complete smoothing of power fluctuations in the best possible cases. The fuzzy controller therefore improves the traditional PI controller providing its simplified and improved tuning over whole control range. Moreover, in place of Ziegler-Nichols rules, Pole placement method (L. Reznik, 2000) has been incorporated to design PI controller in appropriate way. Thenceforth, the FLC rules were subsequently framed to define PI controller gain and update during the simulation. The proposed controller has investigated the performance while in steady state condition along with disturbances such as faults in network, noise in signal.

\section{Modelling of Grid Connected SCIG Wind Farm System}

\subsection{System configuration}

Schematic layout of the wind power plant is analyzed. It consists of an equivalent aggregated $6 \mathrm{MW}$ wind farm (consist of $4 \times 1.5 \mathrm{MW}$ SQIG) propelled by an equivalent aggregated turbine shown in Figure 1.Generator output power is sustained in nominal value using controller.

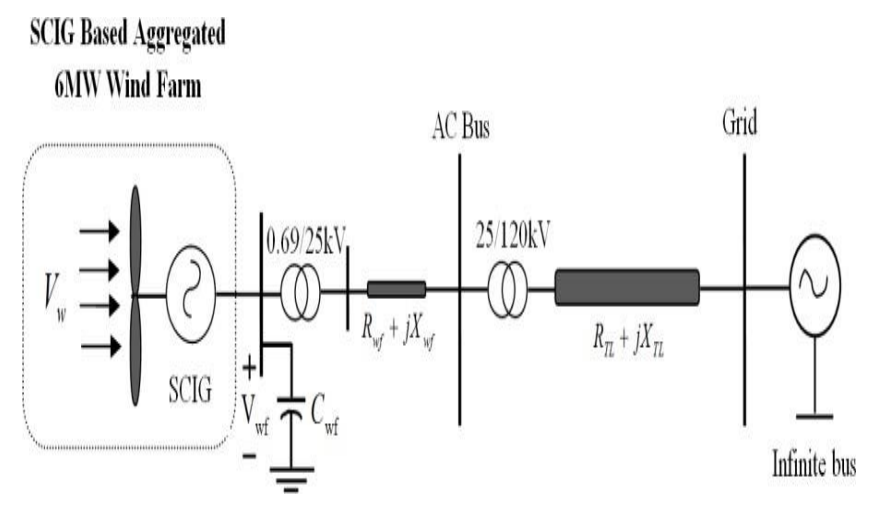

Figure.1 Schematic layout of the wind power plant adjoining the observed grid

If the wind is above its average speed of $9 \mathrm{~m} / \mathrm{s}$. The speed varies approximately $1 \mathrm{p} . \mathrm{u}$. at no load and $1.005 \mathrm{p} . \mathrm{u}$ under conditions of maximum loading.

\subsection{Modelling of wind turbine}

The associated rotor output is directly proportionate to the cube of wind speed

$$
P=\underset{m}{1 / 2} \underset{m}{2} \rho C(\lambda, \underset{r}{\beta}) V_{p}^{3} \quad w
$$

The standard wind turbine is defined by the power coefficient $(\mathrm{C} \mathrm{p})$ which depends on the rotor-tip ratio and the pitch-angle blade ratio .

$$
C_{p}(\lambda, \beta)=c_{1}\left(c_{2} / \lambda_{l}-c_{3} \beta-c_{4}\right) e^{-c_{5} / \lambda_{i}}+c_{6} \lambda
$$

Where

$$
1-0.008 \beta \quad \beta^{3}+1
$$

The coefficients $c_{1}-c_{6}$ are $c_{1}=0.5176, c_{2}=116, \mathrm{c} 3=0.4$,

$c_{4}=5, c_{5}=21$ and $c_{6}=0.0068$ and the blade tip-speed $(\lambda)$ is defined as:

$$
\lambda=\frac{\text { the blade's tip speed }}{\text { Wind velocity }}=\frac{\omega R}{V_{\mathrm{w}}}
$$

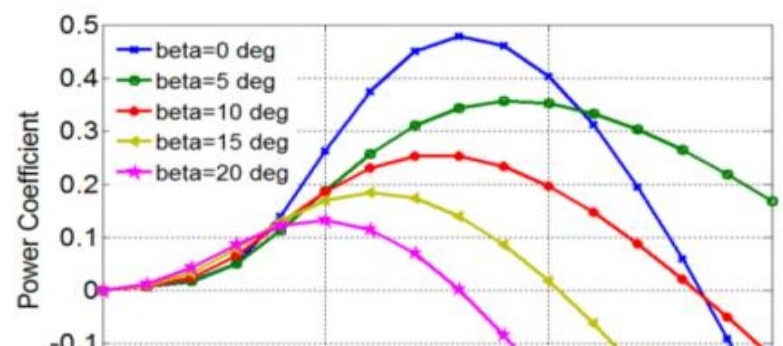


Figure 2 Wind turbine $\mathrm{C} p$ curve

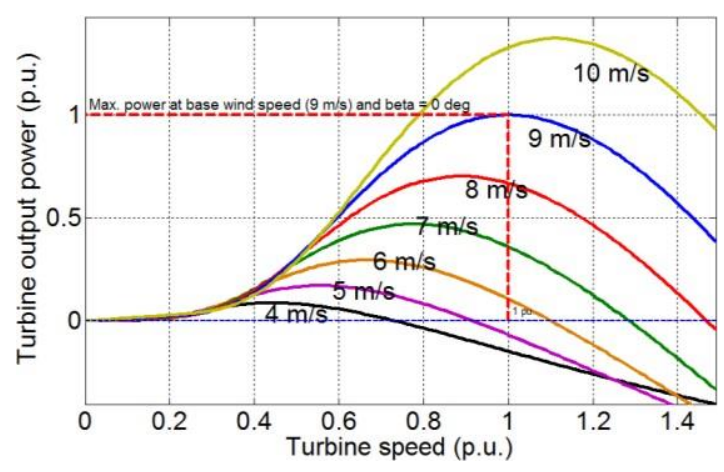

Figure 3 Power characteristics of the turbine

The average power output of the wind turbine at an equivalent wind speed is as shown in figure 3 with the aid of the $C_{p} / \lambda$ curve as seen in Figure 2 for numerous wind speeds. It could be seen from Figs. 2 and 3 defining the characteristics of the turbine that it is possible to excerpt the maximum energy with the aid of the respective rotor speed at any wind speed. Furthermore, if the wind velocity $\left(\mathrm{V}_{\mathrm{w}}\right)$ surpasses the rated wind speed, the turbine's output power can exceed the maximum capacity and hence the wind turbine's input energy is reduced using the pitch controller.

\subsection{Regions of Operation (WT)}

The maximum power can be obtained during this partial load area by maintaining the power coefficient (CP) at maximum location in the wind turbine; we can obtain more power with optimum values using tip-speed ratio and pitch angle.

$$
\beta \quad C_{p \max }=C_{g} \quad \beta=\beta_{o p t} \lambda=\lambda_{\text {opt }}
$$

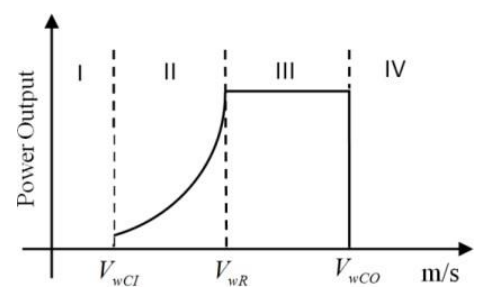

Figure 4 Regions of Operation (WT)

\subsection{Modeling of SCIG}

The reference frame a-b-c is translated to the coordinate system of the d-q axis for the SCIG modeling. The flux relation equations of the wind turbine were discussed-powered SCIG can be written in a coordinate system per unit dq axis as (M. Q. Duong, 2014): 


$$
\begin{aligned}
& p \varphi_{d s e}=\omega_{b a}\left(V_{d s}+R_{s e} i_{d s}+\varphi_{q s}\right) \\
& p \varphi_{q s e}=\omega_{b a}\left(V_{q s}+R_{s e} i_{q s}-\varphi_{d s}\right) \\
& p \varphi_{d r}=\omega_{b a}\left(V_{d r}-R_{r} i_{d r}\right)+\left(\omega_{b}-\omega_{r}\right) \varphi_{q r} \\
& p \varphi_{q q}=\omega_{b a}\left(V_{q r}-R_{r} i_{q r r}\right)-\left(\omega_{b}-\omega_{r}\right) \varphi_{d r}
\end{aligned}
$$

Torque Equation as

$$
T_{e}=\varphi_{d s} i_{q s}-\varphi_{q s} i_{d s}
$$

Equation of dynamic motion as

$$
p \omega=\frac{\omega_{b}\left(T_{m}-T_{e}\right)}{2 H}
$$

\section{Pitch-angle controller}

The Pitch angle system has an important role in the integrated wind energy systems at SCIG. The pitch - angle controller's The main goal is to produce as much actual SCIG power output from the same wind as possible under different potential wind conditions (Bamila Virgin Louis, 2021; Vasanth, V, 2018) and send it to the grid without creating any voltage and frequency variations. The Figure 5 shows the schematic configuration of pitch angle control system. The discrepancy between the specific reference / set power (PSET) and the real measurement power / feedback (PMEAS) happens, it induces a PERR error signal to be corrected by $\mathrm{C}(\mathrm{s})$ controller by adjusting the pitchangle of the rotor tip.

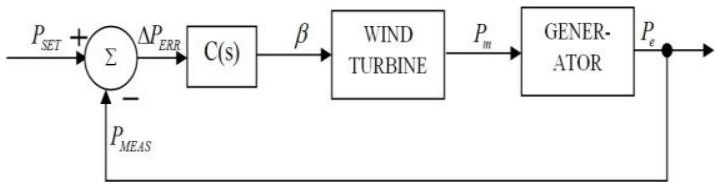

Figure 5 Functional block of Pitch angle control Mechanism

\subsection{Modal control theory based design of PI pitch-angle controller}

This section explored a modal adaptive control approach to the development of a PI pitch angle control system with the generator for the given wind turbine. The aim is to construct a PI controller in such a way as to allocate accurately the own values to be assigned on a very complex plane.

\subsection{Wind turbine generator system linearization}

The nonlinear equation of the SCIG wind energy system as defined in Section 2 has been normalized around over a minimal operating conditions to obtain a set of generalized linear derivative coefficients of the system as follows:

$$
\begin{aligned}
p X & =A X+B U+V W \\
Y & =C X+D U
\end{aligned}
$$

Where $\mathrm{X}, \mathrm{Y}, \mathrm{U}$ and $\mathrm{W}$ are the state vector, the yield variable, its extrinsic vector and the input disturbance vector are the correct dimensional constant matrices. Holding $\mathrm{D}=\mathrm{V}=0$ will ignore the variation term and extrinsic data of the state space equation in order to design the PI pitch controller (12). The condition vector XT can be represented as

$$
X=\left[X_{w f}, X_{m e c h}\right]
$$

Where $X_{w f}$ and $X_{m e c h}$ are structures include wind farm vectors and hydraulic wind turbine structures, respectively. The Eigen value analysis was performed for the wind farm system as represented by its state-space model (12) without taking into account pitch-angle monitoring to determine machine stability and the result obtained are as shown in Table 1. In fact, the second column of Table 1 lists the analysis system eigen values at the wind 
speed of $V_{w}=9 \mathrm{~m} / \mathrm{s}$ in which its eigen values are displayed $\Lambda_{1}-\Lambda_{10}$ represent the electrical modes associated with $X_{w f}$ and the eigen values $\Lambda_{11}-\Lambda_{21}$ represent the mechanical modes associated with $X_{\text {mech }}$. From the Table 1, It is noted that all the system eigen values studied are positioned mostly on left hand side of the S- plane (Sampathkumar, 2020; Shankar, 2020; Garikapati,P, 2020) The system eigen values, however are close to the imaginary axis and need to be further enhanced by the pitch angle controller which can be designed using the pole positioning method as addressed below.

\subsection{PI pitch -angle control Modelling}

It is seen that deviation between $\mathrm{P}_{\mathrm{MEAS}}$ and $\mathrm{P}_{\mathrm{SET}}$ results in the active power error deviation $\left(\Delta \mathrm{P}_{\mathrm{ERR}}\right)$. As a result, the PI controller employed $\Delta \mathrm{P}_{\mathrm{ERR}}$ as a feedback signal to produce a pitch angle signal $(\beta)$ to boost the damping characteristics of the modes. $\left(\Lambda_{11}, 12\right)$ described in Table1. Therefore the output signal in equation (12) can be modified as:

and

$$
Y=\Delta P_{E R R}
$$

$$
U=\beta
$$

It's the vector input. The H(s) transfer function of PI controller in the s-domain is given by

$$
H(s)=\frac{U(s)}{Y(s)}=\frac{\beta(s)}{\Delta P_{E R R}(s)}=\left(K_{P}+\frac{K_{I}}{s}\right)
$$

Where $K_{P}$ and $K_{I}$ are the gains from PI Controller. Two unknowns concerning the PI controller $K_{P}$ and $K_{I}$ can be determined through the use of modal theory of control. The primary step to achieve the Laplace transformation of equations (12)-(14) this is to acquire governing equations in the S-Domain.

$$
U(s)=Y(s) * H(s)=C X(s) * H(s)
$$

Combining equations (14)-(16)

$$
s X(s)=\{A+B[H(s) * C(s)]\} X(s)
$$

The device with closed loop system consist of PI controller's characteristic equation is given by

$$
\operatorname{det}\{s I-[A+B H(s) C]\}=0
$$

Since the PI controller includes the wind turbine generator system being studied constitutes a (SISO), equation (18) is a vector quantity consequently. The Proportional Integral controller gain $\left(K_{P} \& K_{I}\right)$ can be identified by substituting in to equation pre-specified complex pairs combine their own values with the allocated poles (18). Table 1 third section addresses the Eigen values with PI controller for the wind turbine being studied. Clearly it can be noticed that $\Lambda_{11,12}$ has been exactly placed on the complex plane's desired position. This improved the damping ratio of $\Lambda_{11,12}$ (shown in brackets) has been improved from 0.217 to 0.222 .

Table 1 the studied wind farm Eigen values ( $\mathrm{rad} / \mathrm{sec})$ under the speed of $9 \mathrm{~m} / \mathrm{s}$ 


\begin{tabular}{|c|c|c|}
\hline Eigen value No. & WF without pitch angle controller & WF with PI pitch angle controller \\
\hline$\Lambda_{1,2}$ & $-251.32 \pm j 514.37$ & $-251 \pm j 514$ \\
$\Lambda_{3,4}$ & $-86.66 \pm j 688.65$ & \\
$\Lambda_{5}$ & -491.76 & $-86.7 \pm j 689$ \\
$\Lambda_{6,7}$ & $-87.99 \pm j 688.16$ & -92 \\
$\Lambda_{8,9}$ & $-11.56 \pm j 23.59$ & $-88 \pm j 688$ \\
$\Lambda_{10}$ & -34.84 & $-11.6 \pm j 23.6$ \\
& & -34.8 \\
\hline$\Lambda_{11,12}$ & $-1.75 \pm j 7.89[\mathbf{0 . 2 1 7}]$ & $-1.9 \pm j 8.33 *[\mathbf{0 . 2 2 2}]$ \\
$\Lambda_{13,14}$ & $-23.97 \pm j 432.47$ & $-24 \pm j 432$ \\
$\Lambda_{15}$ & -2.72 & $-22 \pm j 432$ \\
$\Lambda_{16,17}$ & $-22.04 \pm j 432.25$ & -0.978 \\
$\Lambda_{18,19}$ & $-2.57 \pm j 9.78$ & $-2.57 \pm j 9.78$ \\
$\Lambda_{20,21}$ & -4.54 & -4.54 \\
\hline$\Lambda_{22}$ & & - \\
\hline
\end{tabular}

* denotes the exactly assigned Eigen values

\subsection{Hybrid pitch angle controller}

The output active power of Synchronous compensated Induction Generator is compared with reference active power and their power difference from FLC is provided as an input to hybrid controller

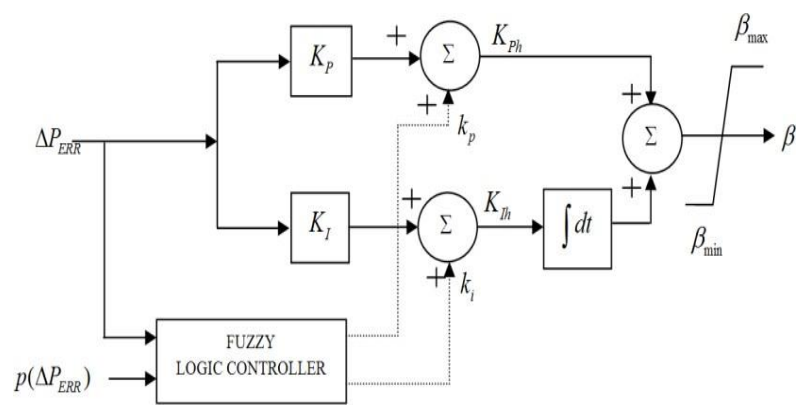

Figure 6 Proposed Controller Using Fuzzy Logic

$$
\begin{gathered}
K_{P h}=K_{P}+k_{p} \\
K_{I h}=K_{I}+k_{i}
\end{gathered}
$$

The Hybrid controller provides, along with gains, the required pitch angle command signal. The original foundation values are known as $K_{P}$ and $K_{I}$. The efficiency of the wind turbine can indeed be achieved with the simple 
values of $K_{P}=3.6$ and $K_{l}=28$ respectively, using modal static optimization principles. The attempt was made with the commitment that $K_{P h}$ and $K_{I h}$ values achieve desirable values across the baseline values as

According to the convergence of active power calculation $\left(P_{M E A S}\right)$ to set and reference active power $\left(P_{S E T}\right)$ with minimal reaction fluctuation, as quickly as possible.

\section{Performance of the hybrid controller under Disturbances}

The results of developed nonlinear system simulation model in Section 2 are discussed and compared with the damping properties of the proposed system with PI motor applied. Under disrupted conditions Stability performance of the hybrid operated wind farm were studied.

\subsection{SC Fault at Grid side}

On the grid side a Short circuit fault shall be applied for a 10s duration and fault cleared in a time period of 10.05s. Figure 7 shows the various transient responses were obtained in wind farm. The figure provides the information that all quantities will be dropped to lower values during the fault. However when the fault is cleared all quantities are returned with oscillations to their steady state conditions. Hence it proves that the proposed controller model provides an excellent damping in comparison to traditional PI and FLC.

Specially, Figure7 (e) displays the pitch angle profile of the wind turbine with traditional PI, Fuzzy logic and hybrid angle controller. Similar to the PI and Fuzzy logic controllers, the hybrid controller pitch angle has retained a relatively stable pitch angle. (i) In order to reduce the oscillations in the wind farm, Figs. 7(f) and (g) exhibit the variations in the gains $\left(K_{P h}\right.$ and $\left.K_{I h}\right)$ during malfunction of the hybrid pitch-angle controller.

The findings described in Table 2 displays that the pitch hybrid-angle controller outperforms the traditional pitch controller by more efficiently minimizing all of the systems quantities under the predominant transient conditions in the ac grid (e.g. a three phase-fault condition)

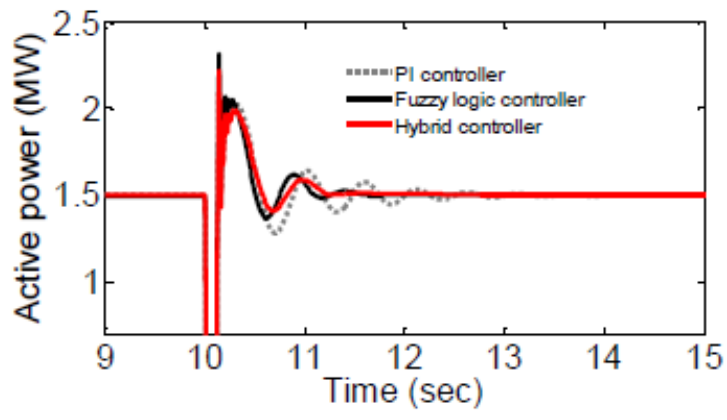

(a)

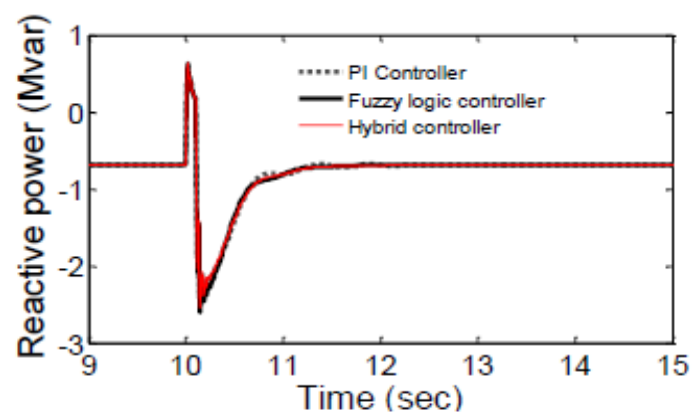

(b) 


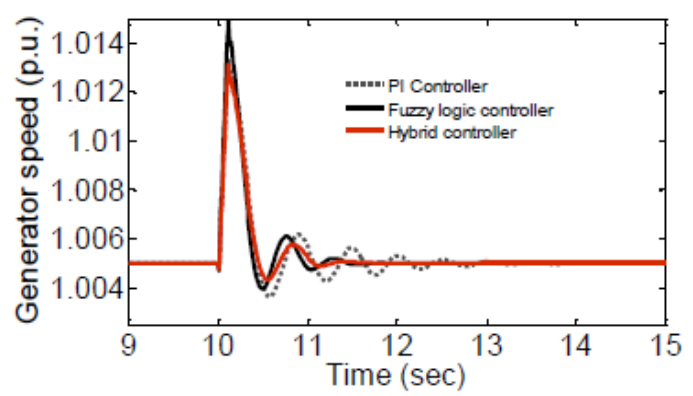

(c)

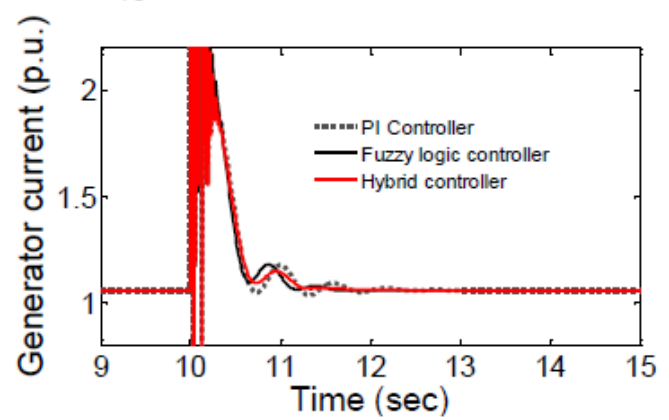

(d)

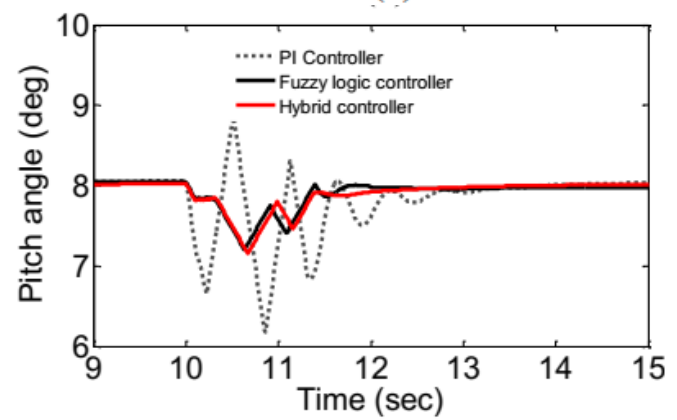

(e)

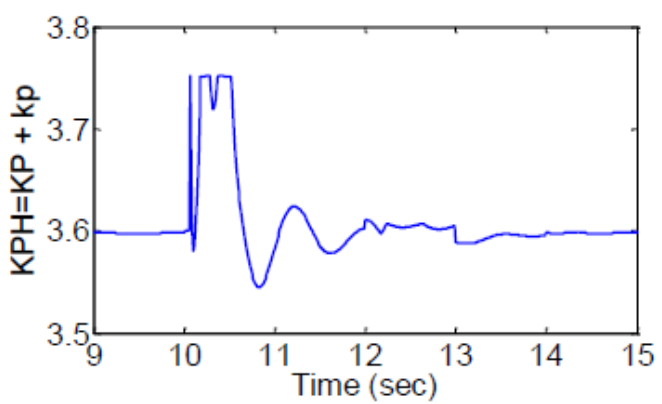

(f) 


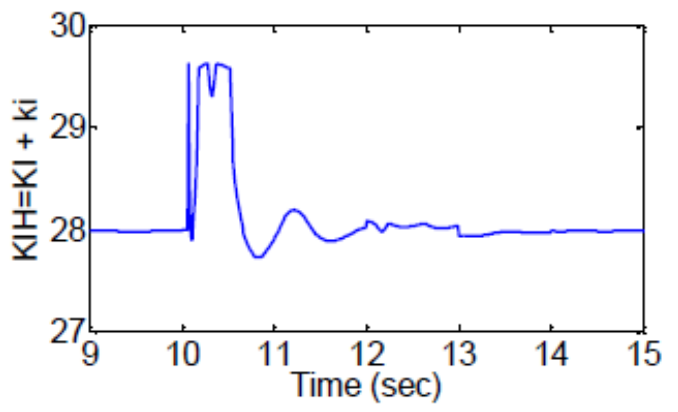

(g)

Figure 7 Transient responses of the studied system under the three phase fault condition (a) IG active power. (b) IG reactive power. (c) IG rotor speed. (d) IG current (e) pitch angle. (f) Profile of KPh . (g) Profile of KIh .

Table 2 Maximum deviation in the quantities of the studied system under the transient fault disturbance

\begin{tabular}{|c|c|c|c|}
\hline Quantities & PI Controller & FLC Controller & Hybrid Controller \\
\hline$\Delta \mathrm{P}$ & 0.1116 & 0.1099 & 0.0998 \\
\hline$\Delta \mathrm{Q}$ & 0.1572 & 0.1523 & 0.1486 \\
\hline$\Delta \mathrm{I}$ & 0.1676 & 0.1608 & 0.1581 \\
\hline$\Delta \mathrm{IG}$ speed & 0.0022 & 0.0020 & 0.0019 \\
\hline$\Delta$ pitch angle & 2.4010 & 2.4257 & 2.3189 \\
\hline
\end{tabular}

\section{Conclusion}

This work proposed PI plus fuzzy logic controller (hybrid) for analyzed system under various disturbances and fault conditions to diminish the power fluctuations. The traditional PI controller is implemented using pole placement technique. Now the gain of the PI controller can be increased or decreased using Fuzzy logic controller according to operational requirements of system. In addition to that proposed hybrid controller, conventional PI and fuzzy logic controller are also employed in order to demonstrate its applicability. All the controllers are tremendously operating with pitch angle controller. However, the proposed hybrid pitch angle controller has provides excellent results compared to conventional controller.

\section{References}

Ackerman .T, (2005) Wind power in power system, John Wiley \& Sons. Ltd.,

Aroulanandam, V. V., Latchoumi, T. P., Bhavya, B., \& Sultana, S. S. (2019). Object Detection in Convolution Neural Networks Using Iterative Refinements. Revue d'Intelligence Artificielle, 33(5) 367-372

Battula, B., Anusha, V., Praveen, N., Shankar, G., \& Latchoumi, T. P. (2020). Prediction of Vehicle Safety System Using Internet of Things. Journal of Green Engineering, 10(4), 1786-1798.

Causebrook .A, D. J. Atkinson, and A. G. Jack, (2007). "Fault ride-through of large wind farms using series dynamic braking resistors, IEEE Transactions on Power Systems 22, 966-975.

Cham, Uddin M. .N, R. S. Rebeiro, (2011) Improved Dynamic and Steady State Performance of a Hybrid Speed Controller Based IPMSM Drive, IEEE Conference 1-8.

Duong M. .Q, F. Grimaccia, S. Leva, M. Mussetta, E. Ogliari, (2014) Pitch angle control using hybrid controller for all operating regions of SCIG wind turbine system, Renewable Energy 70 197-203.

Garasi .P, M. Watanabe, Y. Mitani, (2014). Power Smoothing of Wind Turbine Generator using Fuzzy-PI Pitch Angle Controller, Australasian Universities Power Engineering Conference 1-5.

Garikapati, P., Balamurugan, K., Latchoumi, T. P., \& Malkapuram, R. (2020). A Cluster-Profile Comparative Study on Machining AlSi 7/63\% of SiC Hybrid Composite Using Agglomerative Hierarchical Clustering and $\mathrm{K}$ Means. Silicon, 1-12.

Ghazi .R, and H. Aliabadi, (2010). "Stability improvement of wind farms with fixed-speed turbine generators using braking resistors," 45th International Universities Power Engineering Conference UPEC, Wales, 1-5 Global Wind Energy Council, (2018). http://gwec.net/global- figures / wind-in-numbers / (access on 15-8.

Kanaga Suba .S Raja,Bamila Virgin Louis (2021) 'Optimal Resource Allocation in $5 G$ System using Modified Lion Algorithm', IET Communications, ISSN 1751-8636, 15(1), pp. 126-141. https://doi.org/10.1049/cmu2.12064. (IF: 1.66) 
Latchoumi, T. P., \& Parthiban, L. (2018). Advanced Overlap Community Detection by Associative Rule Mining and Multi-View Ant Clustering. International Journal of Engineering and Technology, 7, 21-29.

Latchoumi, T. P., Loganathan, J., Parthiban, L., \& Janakiraman, S. (2016, August). OFS method for selecting active features using clustering techniques. In Proceedings of the International Conference on Informatics and Analytics (pp. 1-4).

Latchoumi, T. P., \& Parthiban, L. (2016). Secure Data Storage in Cloud Environment using MAS. Indian Journal of Science and Technology, 9, 24-29.

Ou, R., Xiao, X. Y., Zou, Z. C., Li, C. S., and Wu, D. Y. (2015). Application of SFCL to improve the transient voltage stability of grid-connected wind farm with DFIG during grid faults. IEEE International Conference on Applied Superconductivity and Electromagnetic Devices (ASEMD), Shanghai, pages 240- 241.

Reznik . L, O. Ghanayem, A. Bourmistrove, (2000) PID plus fuzzy controller structures for as a design base for industrial applications, energy appl.arti.intell. 13(4) 419-30.

Shankar, G., Latchoumi, T. P., Chithambarathanu, M., Balayesu, N., \& Shanmugapriya, C. (2020). An Efficient Survey on Energy Conservation System with Video Surveillance. Journal of Xian University of Architecture and Technology, 12(7), 100-106.

Sheikh M. R. .I, N. Mondol, and F. Eva, (2012). "Stabilization of wind generator by PWM-VSC controlled SMES," 2nd International Conference on the Developments in-Renewable Energy Technology (ICDRET 2012), Dhaka, $1-5$

Sampathkumar, A., S. Murugan, Ahmed A. Elngar, Lalit Garg, R. Kanmani, and A. Christy Jeba Malar. (2020). "A Novel Scheme for an IoT-Based Weather Monitoring System Using a Wireless Sensor Network." In Integration of WSN and IoT for Smart Cities, pp. 181-191. Springer

Vasanth, A. V., Venkatachalapathy, K., Latchoumi, T. P., Parthiban, L., Sowmia, T., \& OhmPrakash, V. (2018). An Efficient Cache Refreshing Policy to Improve QoS in MANET Through RAMP. In Proceedings of the Second International Conference on Computational Intelligence and Informatics (pp. 369-381). Springer, Singapore.

Wang .L, D. N. Truong, (2013) stability enhancement of DFI based offshore wind farm fed to a multi machine system using a STATCOM, IEEE Transaction on power systems, 28(3) 2882-89.

Yilmas A. .S, Z. Ozer, (2009). Pitch angle control in wind turbines above the rated wind speed by multi-layer perceptron and radial basic function neural networks, Expert Systems with Applications 36(6) 9767 - 75. 